\title{
Six new species and new records of the genus Desmopachria Babington (Coleoptera: Dytiscidae: Hyphidrini) from Brazil and redescription of $D$. varians Wehncke, 1877
}

\author{
Rafael Benzi Braga ${ }^{1,2}$ \& Nelson Ferreira-Jr. ${ }^{1,3}$ \\ ${ }^{1}$ Universidade Federal do Rio de Janeiro (UFRJ), Instituto de Biologia (IB), Departamento de Zoologia, Laboratório de Entomologia. \\ Rio de Janeiro, RJ, Brasil. \\ 2 ORCID: 0000-0003-2421-1681. E-mail: rafaelbenzi@gmail.com \\ 3 ORCID: 0000-0002-5932-7695. E-mail: nferrejr@gmail.com
}

\begin{abstract}
Six new species of the genus Desmopachria Babington, 1841 are described and illustrated from Brazil: $D$. anauine $\mathrm{sp}$. nov., D. carranca sp. nov., D. francischettii sp. nov., D. nigrasphera sp. nov., D. nigricoxa sp. nov. and D. yanomami sp. nov. Desmopachria varians is redescribed and illustrated from syntypes photos and material identified by Dr. Frank Young. New records for eight other species from Brazilian states are presented here: D. amyae Miller, 2001 has a new record from Minas Gerais State, D. grammosticta Braga \& Ferreira-Jr., 2015 have new records from Minas Gerais and São Paulo States, D. granoides Young, 1986 has a new record from Espirito Santo State, D. laevis Sharp, 1882 have new records from Espírito Santo and Parana States, D. leptophallica Braga \& Ferreira-Jr., 2014 has a new record from Paraná State, D. sioli Young, 1980 has a new record from Minas Gerais State, D. striola Sharp, 1887 have new records from Rio de Janeiro and São Paulo States and D. volatidisca Miller, 2001 has a new record from Paraíba States and an unpublished record of D. challeti Miller, 2001 from Brazil.
\end{abstract}

Key-Words. Hydroporinae; Desmopachria; Aquatic beetle; Taxonomy; Neotropical Region.

\section{INTRODUCTION}

The genus Desmopachria Babington, 1841 is composed of small beetles, hardly longer than $2.5 \mathrm{~mm}$, found in a variety of aquatic environments, including ponds, streams, forest pools, bromeliads and pools of tree holes (Miller, 2005). Although very common they are easily overlooked due to their small size. Currently Desmopachria has 125 species found in the Neotropics and southern Nearctic (Miller \& Wolf, 2018; Nilsson \& Hájek, 2018). The group was intensively worked on by Young (1980, 1981a, 1981b, 1981c, 1986, 1989, 1990a, 1990b, 1993, 1995) and more recently by Miller (1999, 2001, 2005, 2018), whereas the Brazilian species were specifically studied by Braga \& Ferreira-Jr. (2010, 2011, 2014). Miller (2001) gave a synopsis of the genus, replaced the subgenera and some species groups created by Young (1980, 1981b, 1981c, 1986, 1990b, 1995) with a system of newly defined species groups that, although not encompassing all the species, greatly facilitated their identification.

Desmopachria varians Wehncke, 1877 is a Brazilian species not difficult to identify due its conspicuous and characteristic elytral colour patterns. Although this species had been described twice: first in Wehncke's 1877 original description and then by Sharp (1882), both descriptions are inadequate by current standards, both omit many of the characters currently used in generic identification. In fact, there is no mention of male genitalia, which is a decisive character for specific identification of many species and necessary for the identification of most species groups. A modern, detailed redescription of $D$. varians, including illustrations of habitus and male genitalia is given here, together with the description of six new species and new records for Brazil.

\section{MATERIAL AND METHODS}

The specimens were examined under a Zeiss Stem SV6 stereoscopic microscope with up to 150x magnification. The measurements were obtained with the aid of a grid ocular reticle with an accuracy of $0.01 \mathrm{~mm}$ mounted on an Olympus 210401 stereomicroscope. The diagnostic range of measurements of structures was emphasized, so the largest and smallest specimens were preferentially measured whenever possible. The specimens were preserved in tubes using $92 \%$ ethyl alcohol. The genitalia were mounted on slides 
in glycerin gel with and without coverslips for a best comparison between old and new illustration methods. Older works (Young, 1981b, 1981c, 1989) clearly illustrate flattened genitalia with coverslips, however more recent works (Gustafson \& Miller, 2012 and Miller \& Wolfe, 2018) have preferred illustrations with more three-dimensional images without coverslips. Genitalia were then stored in microvials within the specimen tube. The figures were made with a Leica M205C stereomicroscope coupled with a Leica DFC450 camera. The images were edited in the program Adobe Photoshop CS6. The elytra lighter color in photos of dissected specimens is an artifact created by the transparency of the elytra when it is not fully closed or removed from the specimen. Because species of this genus usually lack external sexual dimorphism, the only way to determine the sex of specimens is by examining the genitalia. Although several specimens have been dissected only the sex of the holotype was determined in the text.

The terminology used in the descriptions follows that of Young (1995), Miller (2005) and Braga \& Ferreira-Jr. (2014). The specimens are deposited in the Coleção Entomológica Prof. José Alfredo Pinheiro Dutra, Departamento de Zoologia, Universidade Federal do Rio de Janeiro, Brazil (DZRJ) and Instituto Nacional de Pesquisas da Amazônia (INPA).

In the descriptions of the new species all labels accompanying the specimens are listed. First the complete locality label and collection number label are given, followed by type label, quantity of specimens for each locality. The institute where the specimens are deposited are indicated in parentheses. Each label is marked with quotation marks and lines are separated by bars. Information not present on the original labels, such as unknown geographic coordinates or material and colour of the label, are given in square brackets. When the geographic coordinates of a collection place were unknown, the central point of the municipality is presented as coordinates for the specimen.

In the previous descriptions of $D$. varians both authors, Wehncke (1877) and Sharp (1882), do not assigned a type or indicated which material was used for the description, however there are two specimens identified by Wehncke and labeled as syntype in Muséum National D'Histoire Naturelle (MNHN, Paris). Unfortunately there is no information of who informed the types and the labels are typed. The specimens used in this article were identified by comparison with photos of those syntypes and material previously identified by F. Young.

\section{DESCRIPTION OF THE SPECIES}

\section{Desmopachria anauine sp. nov. (Figures 1A-L)}

Diagnosis: Medium size for genus $1.7 \mathrm{~mm}$; presence of fine transverse suture on apical ventrite (Fig. 1C); median lobe of aedeagus in dorsal view with basal half broad and apical half narrower, apex pointed arch (Fig. 1J); each lateral lobe apically divided into two rami: a ventral rami with acute apex and a dorsal rami with rounded apex (Figs. 11, L).

Description: Holotype male: total length $1.7 \mathrm{~mm}$; maximum width of body $1.2 \mathrm{~mm}$; elytral length $1.2 \mathrm{~mm}$; maximum width of pronotum $0.9 \mathrm{~mm}$.

Colouration (Figs. 1A-C): Head and pronotum testaceous, each elytron dark brown (Figs. 1A-B); venter testaceous with exception of light brown metacoxae and abdomen (Fig. 1C).

Structure and sculpture: Body rounded with very fine, shallow and scarcely distributed punctuation; clypeus beaded; antennae with rounded scape, pedicel narrower and longer than others antennomeres, antennomeres 5-9 slightly expanded in apical half. Pronotum short and wide, with lateral bead and without basal striae; elytral suture margined. Prosternal process broad, apically pointed, shallowly concave. Apical ventrite with a fine transversal suture (Fig. 1D).

Male genitalia (Figs. 1E-M): Median lobe in dorsal view with basal half broad and apical half narrower, pointed arch apex (Fig. 1J); lateral margins straight until the apex; in lateral view basal and middle thirds of dorsal side rounded and apical third straight, ventral margin straight, apex sickle shape (Fig. 1L). Lateral lobes with apical half divided into two ramus: dorsal one straight, longer, with rounded apex bearing few long setae on its inner margin; ventral rami, shorter, rounded in dorsal margin and straight on ventral margin and apex pointed (Fig. 11); few setae and a row of short setae occur on dorsal margin; in lateral-outer view lateral lobe with only apex of ventral branch visible, base broadened, toward middle of lateral lobe length, dorsal rami narrowing to a rounded apex on which a visible a diagonal concave line (Fig. 1M).

Intraspecific variation: Small variations of elytra and pronotum width: maximum width of body 1.0-1.3 mm; maximum width of the pronotum $0.8-0.9 \mathrm{~mm}$.

Taxonomic notes: This new species belongs to the Desmopachria nitida group sensu Miller (2001) because of the lateral lobes of aedeagus being deeply bifid with the apex divided into two distinct rami. The parallel-sided median lobe with apex pointed arched in combination with ventral rami branch of the lateral lobe having a rounded external margin and pointed apex is unique to this group. Species with similar genitalia are $D$. liosomata Young 1986, which has the median lobe apex almost truncated and ventral rami of lateral lobe with rounded apex, and D. psarammo Miller 1999, with abruptly pointed median lobe apex and ventral rami branch with straight external margin. In addition, both species are smaller than $D$. anauine sp. nov. and D. psarammo has elytral macula, which are absent in the new species. According to Miller \& Wolfe (2018) description of $D$. nitida group, D. anauine is the only species of the group with transverse suture in 

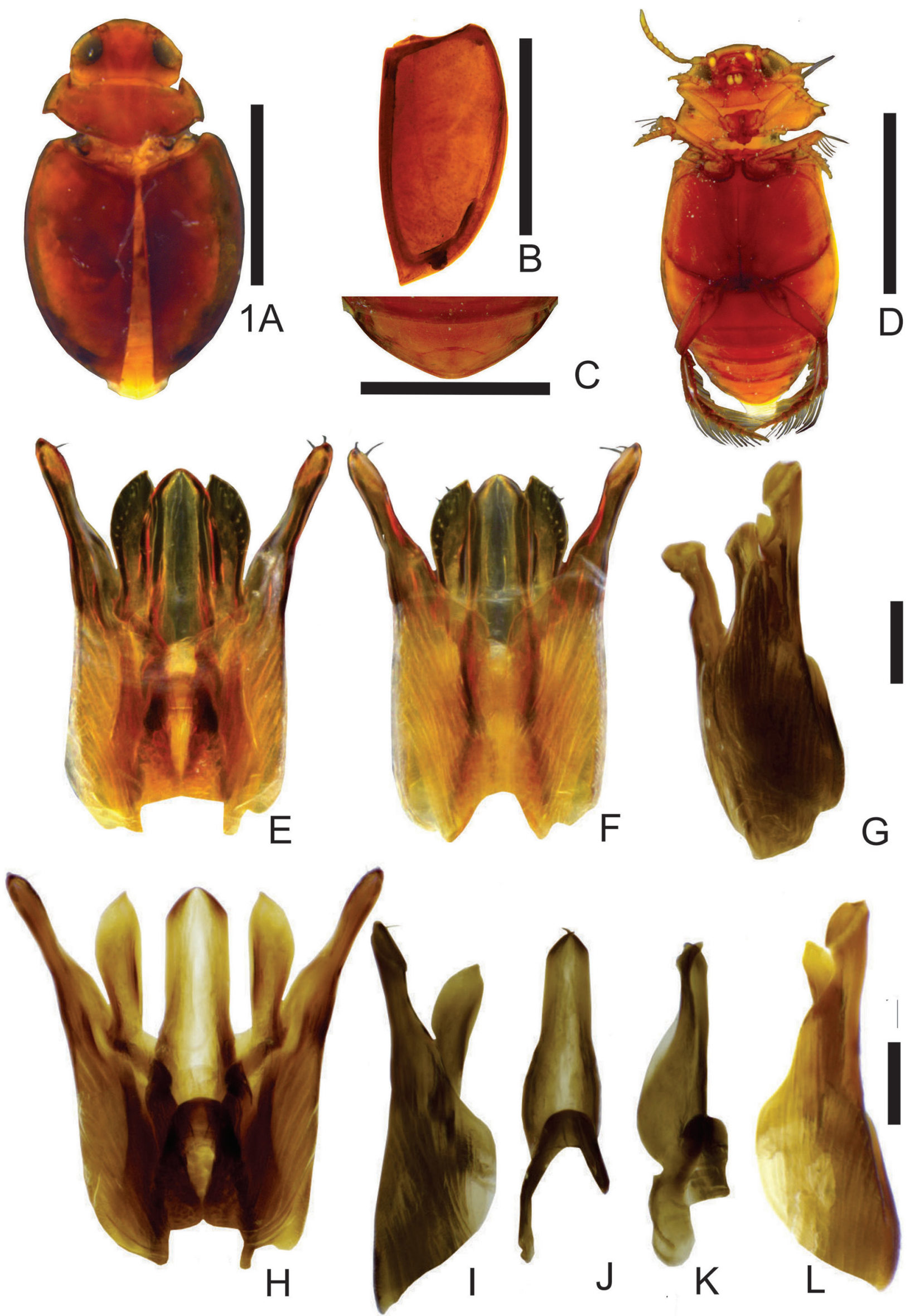

Figures 1A-L. Desmopachria anauine. (A) Dorsal View. (B) Colour pattern of elytron. (C) Apical ventrite. (D) Dorsal view. (E-L) Male genitalia. (E) Dorsal view. (F) Ventral view. (G) Lateral view. (H) Coverslip dorsal view. (I) Lateral lobe dorsal view. (J) Median lobe dorsal view (apex slight damaged). (K) Median lobe lateral view. (L) Lateral lobe lateral view. Figs. 1A-D scale bars $=1 \mathrm{~mm}$, Figs. 1E-L scale bars $=0.1 \mathrm{~mm}$. 
the last sternite, but it should be emphasized this characteristic was not considered in many ancient descriptions and this suture can be overlooked in some species.

Type material: Holotype male: "Brasil, Amazonas, Novo Airão, Rio/ Negro, Arquipélago de/ Anavilhanas, Lago do Prato,/ [2044'44"S, 6044'42"W]/ 13.ii.1982. Nessimian J.L. [paper white label]", "INPA [plastic blue label]", "HTYPE [plastic red label]" (INPA). Paratypes: "Brasil, Amazonas, Novo Airão/, Rio Negro, Arquipélago de/ Anavilhanas, Lago do Prato,/ [2044'44"S, 6044'42"W]/ 13.ii.1982. Nessimian J.L. [paper white label]", "490 [plastic blue label]" "PTYPE [plastic red label]" (1 ex.) (DZRJ). "Brasil, Amazonas, Novo Airão, Rio/ Anavilhanas, Rio Negro, Lago Xidaua,/ [2044'44"S, 6044'42"W],/ 25.i.1982, Nessimian J.L. [paper white label]”, "2673 [plastic blue label]”, “PTYPE [plastic red label]" (4 exs.) (DZRJ).

Etymology: The specific name anauine refers to "Rio Anauiné", a river that by corruption of word became "Anavilhena" or "Anavilhana", and is part of the second largest fluvial archipelago in the world, as well as the place of origin of the type material of this new species. It is a noun in the nominative singular standing in apposition.

Geographic distribution: Only known from the type locality on Anavilhanas archipelago in Amazonas State of Brazil.

\section{Desmopachria carranca sp. nov. (Figures 2A-L)}

Diagnosis: Large size for genus 2.3-2.4 mm; head testaceous, pronotum testaceous with dark brown macula on base (Fig. 2A), each elytron testaceous with diffused dark brown macula on disk (Fig. 2B); male median lobe of aedeagus smaller than lateral lobes and in dorsal view narrowing and apex truncated with a small reentrancy in middle (Figs. 2G, I).

Description: Holotype male: total length $2.4 \mathrm{~mm}$; maximum width of body $1.6 \mathrm{~mm}$; elytral length $1.6 \mathrm{~mm}$; maximum width of the pronotum $1.3 \mathrm{~mm}$.

Colouration (Figs. 2A-C): Head testaceous; pronotum testaceous with dark brown macula on base; each elytron diffused dark brown in disk and testaceous in base and lateral. Venter testaceous.

Structure and sculpture: Body rounded, dense punctuation; head and pronotum with fine, shallow punctures on dorsal surface, ventral surfaces inconspicuously punctuated; elytral with fine, deep punctures on dorsal surface, line of broad, shallow punctures along elytral suture margin. Clypeus slightly up-turned; antennae with rounded scape, pedicel narrower and longer than others antennomeres, antennomeres 5-9 slightly expanded in apical half. Pronotum short and wide, with lateral bead and without basal striae; elytral suture margined; prosternal process strongly forked apically, area between rami forming a deep pit. Ventral surface of metatibia covered with short and wide spines. Apical ventrite smooth without sutures or marks.

Male genitalia (Figs. 2D-K): Median lobe of aedeagus one quarter shorter than lateral lobes (Fig. 2G); in dorsal view triangular shaped, narrowing toward, apex truncated with a small medial notch (Fig. 2l); in lateral view narrowing toward apex, bended in half-length to dorsal side, apex spoon like (Fig. 2H). Lateral lobes in dorsal view triangular with a dense row of setae on inner margin of apical third (Fig. 2H); in lateral view basal third expanded, middle and apical thirds straight gently narrowed to apex (Fig. 2L).

Intraspecific variation: Total length 2.3-2.4 mm; maximum width of body 1.6-1.7 $\mathrm{mm}$; elytral length $1.6-1.7 \mathrm{~mm}$.

Type material: Holotype male: "Brasil, Minas Gerais, Itabirito, Vale/ dos Tropeiros, Cachoeira da/ Carranca,/ $20^{\circ} 01^{\prime} 26^{\prime \prime} \mathrm{S}, 43^{\circ} 38^{\prime} 39^{\prime \prime} \mathrm{W}, /$ 10.x.2010, Ferreira-Jr N.,/ $996 \mathrm{~m}$ [paper white label]", "5959 [plastic blue label]" "HTYPE [plastic red label]” (DZRJ). Paratypes:"Brasil, Minas Gerais, Itabirito, Vale/ dos Tropeiros, Cachoeira da/ Carranca./ $20^{\circ} 12^{\prime} 26^{\prime \prime} \mathrm{S}, 43^{\circ} 38^{\prime} 39^{\prime \prime} \mathrm{W} / 10 . x .2010$ Ferreira-Jr N./ $996 \mathrm{~m}$ [paper white label]", "5960 [plastic blue label]", "PTYPE [plastic red label]" (22 exs.) (DZRJ).

Taxonomic notes: This new species belongs to the D. portmanni group sensu Miller (2001) in having the prosternal process sexually dimorphic among the species of this group and for its median lobe shorter than lateral lobes. The new species is comparable with $D$. aurea Young 1980, D. specula Sharp 1887, D. variegata Sharp 1882 and D. ukuki Braga \& Ferreira-Jr., 2014, but all these are smaller in body size. $D$. carranca sp. nov. is similar in size to D. itamontensis Braga \& Ferreira-Jr., 2014, D. undulatosterna Braga \& Ferreira-Jr., 2011 and D. zetha Young 1995 , but all these species have different colour pattern. Moreover D. itamontensis and D. undulatosterna share conspicuous large punctuations, absent in $D$. carranca sp. nov., whereas $D$. zetha has a median lobe in dorsal view straight not triangular in shape, ending in a rounded apex without an apical notch.

Etymology: The specific name refers to the Carranca falls, where the type material of this species has been collected. It is a female noun in the nominative singular.

Geographic distribution: Known only from the Minas Gerais State of Brazil.

\section{Desmopachria francischettii sp. nov. (Figures 3A-K)}

Diagnosis: Large size for the genus $2.4 \mathrm{~mm}$. Each elytron testaceous with two transversally dark brown fas- 

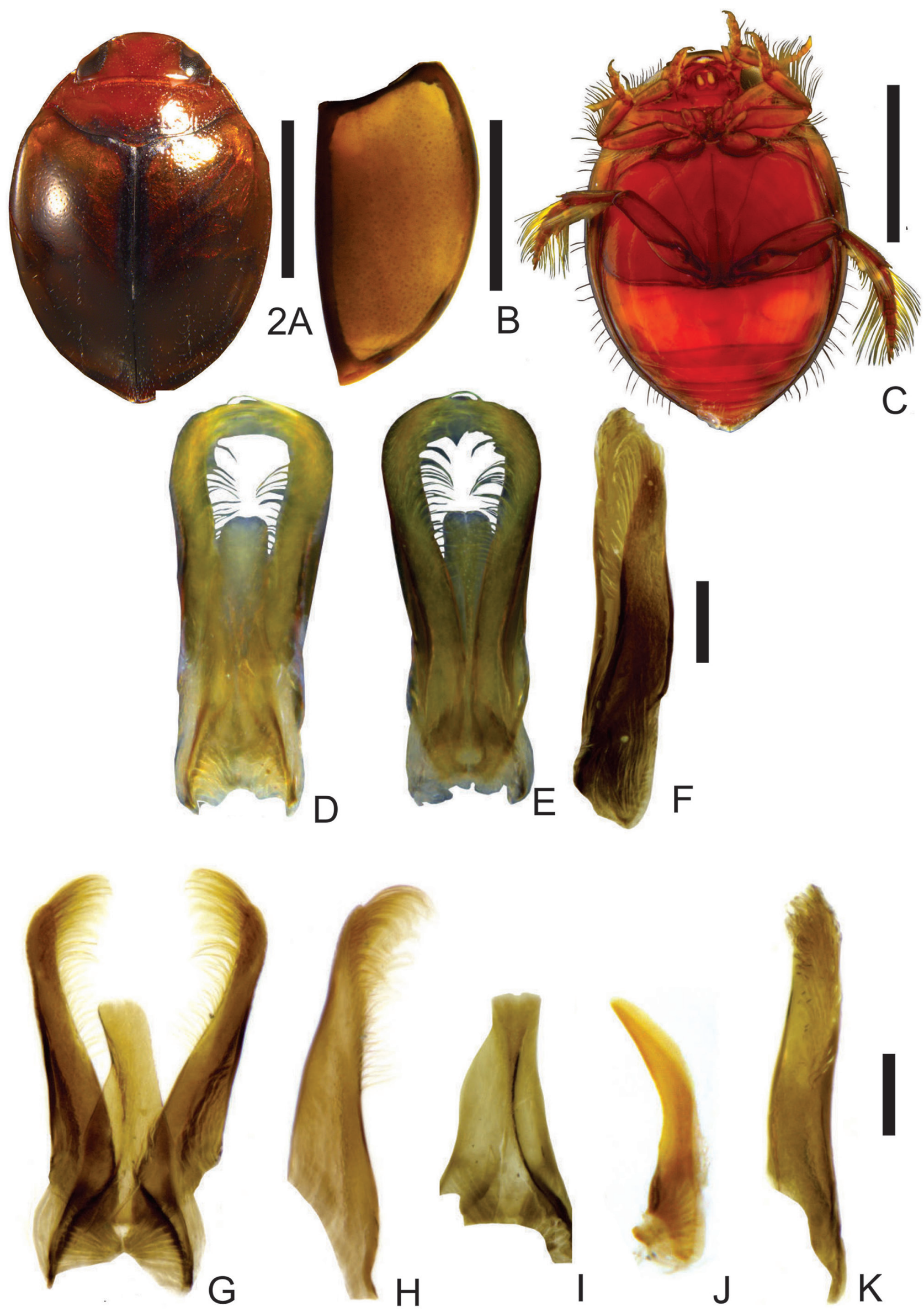

Figures 2A-K. Desmopachria carranca. (A) Dorsal View. (B) Colour pattern of elytron. (C) Ventral view. (D-K) Male genitalia. (D) Dorsal view. (E) Ventral view. (F) Lateral view. (G) Coverslip dorsal view. (H) Lateral lobe dorsal view. (I) Median lobe dorsal view. (J) Median lobe lateral view. (K) Lateral lobe lateral view. Figs. 2A-C scale bars $=1 \mathrm{~mm}$, Figs. 2D-K scale bars $=0.1 \mathrm{~mm}$. 

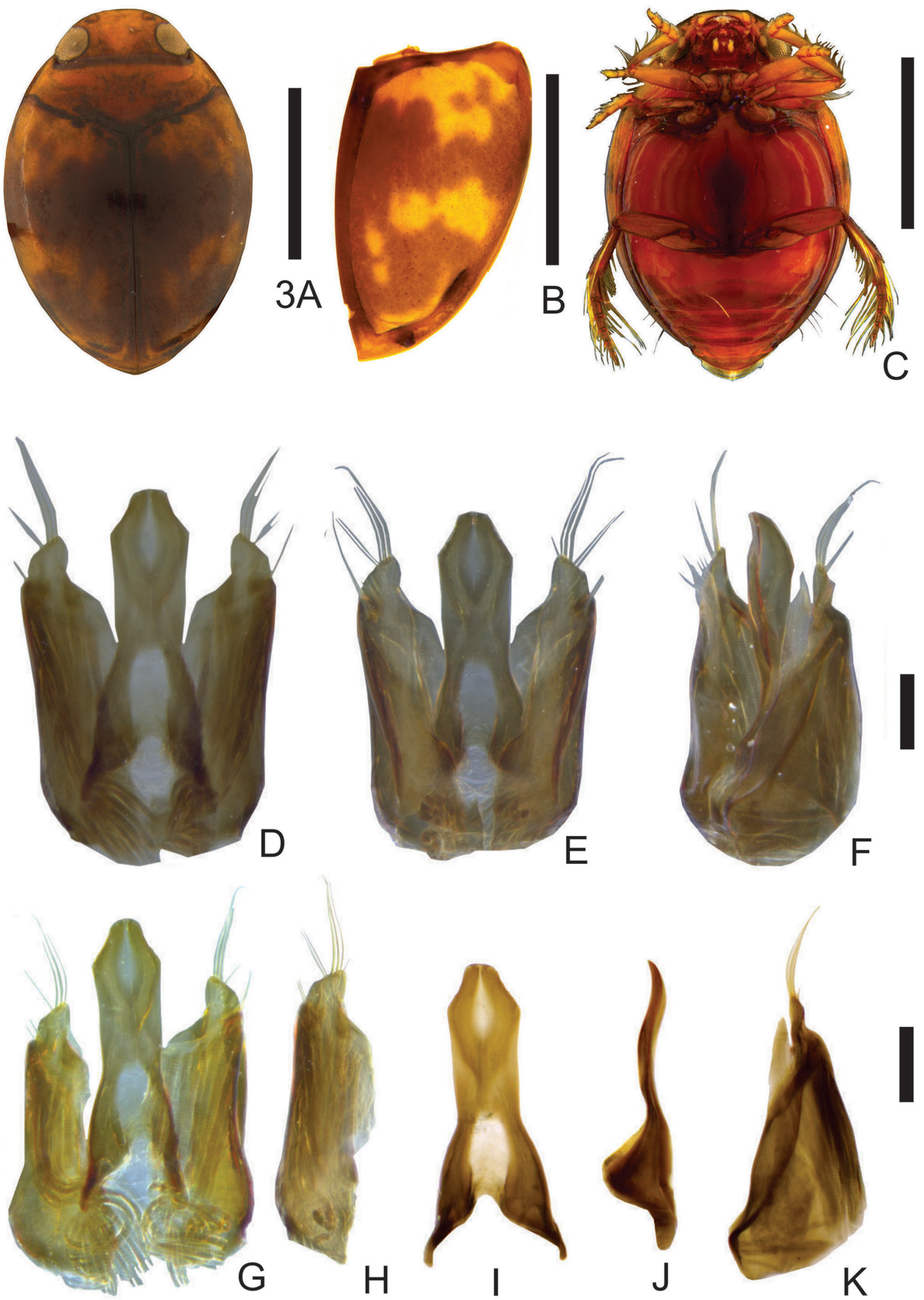

Figures 3A-K. Desmopachria francischettii. (A) Dorsal View. (B) Colour pattern of elytron. (C) Ventral view. (D-K) Male genitalia. (D) Dorsal view. (E) Ventral view. (F) Lateral view. (G) Coverslip dorsal view. (H) Lateral lobe dorsal view. (I) Median lobe dorsal view. (J) Median lobe lateral view. (K) Lateral lobe lateral view. Figs. 3A-C scale bars $=1 \mathrm{~mm}$, Figs. 3D-K scale bars $=0.1 \mathrm{~mm}$. 
ciae (Fig. 3B). Median lobe in dorsal view with middle third straight and apical third narrowed, apex truncated (Fig. 3l), in lateral view with apical half thin and waved (Fig. 3j). Lateral lobe robust in both view, in lateral view lateral lobe triangular shaped (Figs. 3H, L).

Description: Holotype male: total length $2.4 \mathrm{~mm}$; maximum width of body $1.7 \mathrm{~mm}$; elytral length $1.7 \mathrm{~mm}$; maximum width of the pronotum $1.2 \mathrm{~mm}$.

Colouration (Figs. 3A-C): Head testaceous; pronotum testaceous with dark brown base; ventral surface testaceous (Fig. 3A); elytron testaceous with two irregular transversal dark brown fasciae one in the middle of elytron and other near the apex (Fig. 3b). Ventral surface reddish brown (Fig. 3 C).

Structure and sculpture: Body very rounded. Head and pronotum with very fine, shallow and scarcely distributed punctures; elytral surface with very fine, shallow and dense punctures, a line of shallow punctures along the elytral suture, it coarse puctures near the elytral base and smaller punctures along the elytral length. Clypeus truncated; antennae with rounded scape, pedicel narrower and longer than others antennomeres, antennomeres 5-9 slightly expanded in apical half. Pronotum short and wide, with lateral bead and without basal striae. Prosternal process broad, apically rounded, shallowly concave. Apical ventrite smooth without sutures or marks.

Male genitalia (Figs. 3D-K): Median lobe of aedeagus in dorsal view with basal third broad, middle third straight and apical third narrow, apex truncated (Fig. 3l); in lateral view with basal half broad, almost triangular and apical half thin and waved (Fig. 3J). Lateral lobe robust in both view, in dorsal view almost rectangular narrow gently to rounded apex, presence of a few long setae on the apex and outer margin (Fig. $3 \mathrm{H}$ ); in lateral view lateral lobe triangular (Fig. 3K).

Intraspecific variation: Total length 2.3-2.5 mm; maximum width of body $1.7 \mathrm{~mm}$; elytral length $1.7 \mathrm{~mm}$; maximum width of the pronotum 0.9-1.0 mm.

Type material: Holotype male: "Brasil, Minas Gerais, Paula Candido,/ Córrego dos Barros, Veg./ Marginal/ 2050'37"S, 4955'32"W/ 19.ix.2004, Francischetti/ C.N.\& Salles F., 686 m [paper white label]”, “5952 [plastic blue label]" "HTYPE [plastic red label]" (DZRJ). Paratypes: "Brasil, Minas Gerais, Paula Candido,/ Córrego dos Barros, Veg./ Marginal/ 2050'37"S, 49 $55^{\prime} 32^{\prime \prime} \mathrm{W} /$ 19.ix.2004, Francischetti/ C.N.\& Salles F., 686 m [paper white label]", "5953 [plastic blue label]", "PTYPE [plastic red label]" (6 exs.) (DZRJ).

Taxonomic notes: This species best fits in the $D$. glabricula group sensu Miller (2001) since it has the characteristic sclerotized lateral lobe, however the genitalia is very simple without folds in the lateral lobe, a bifurcated and/ or ornate male median lobe, which is present in other species of the group. Therefore, the genitalia of the new species is deviating compared to other species in the group.

Etymology: The specific name is an homage to Dr. Cesar Francischetti, one of the collectors of material.

Geographic distribution: So far known only from the Minas Gerais State of Brazil.

\section{Desmopachria yanomami sp. nov. (Figures 4A-L)}

Diagnosis: Small size for the genus 1.3-1.4 mm. Male median lobe triangular (Fig. 4J-K); Lateral lobe with the apical half divided in two flat and broad ramus; dorsal rami short and less wide, ventral rami with a apex truncated and a tuft of small setae near of outer angle (Fig. 4l).

Description: Holotype male: total length $1.4 \mathrm{~mm}$; maximum width of body $0.9 \mathrm{~mm}$; elytral length $0.9 \mathrm{~mm}$; maximum width of the pronotum $0.3 \mathrm{~mm}$.

Colouration (Figs. 4A-C): Head yellow; pronotum yellow with base dark brown; each elytron dark brown with scattered yellow maculae in laterals (Figs. 4A-B). Venter yellow (Fig. 4C).

Structure and sculpture: Body rounded. Head and pronotum with very fine, shallow scarcely distributed punctures; each elytron with very fine, shallow and densely distributed punctures. Anterior clypeal margin thin, translucent and up-turned; Antennae with very rounded scape longer than two antennomeres united, pedicel narrower with same length of scape, antennomeres 5-9 slightly expanded in apical half. Pronotum short and wide, with lateral bead and without basal striae; prosternal process broad, apically rounded, shallowly concave. Elytral suture without margin. Ventral surface of metatibia covered with short and wide spines. Apical ventrite with a very fine transversal line (Fig. 4D).

Male genitalia (Figs. 4E-L): Median lobe in dorsal view narrowing toward to pointed apex (Fig. 4J); in lateral view almost triangular with a convexity on ventral margin of base (Fig. 4K). Lateral lobe with the apical half divided in two flat and broad rami (Figs. 4F-H), dorsal rami short and less wide, ventral rami with a apex truncated and a tuft of small setae near of outer angle (Fig. 4l); in lateral view lateral lobe almost triangular shaped slight bended to ventral side (Fig. 4L).

Intraspecific variation: Anterior clypeal margin sexually dimorphic, beaded in female and not conspicuously translucent. Total length 1.3-1.4 mm; maximum width of body $0.9-1.0 \mathrm{~mm}$; maximum width of the pronotum 0.8-1.0 mm. 

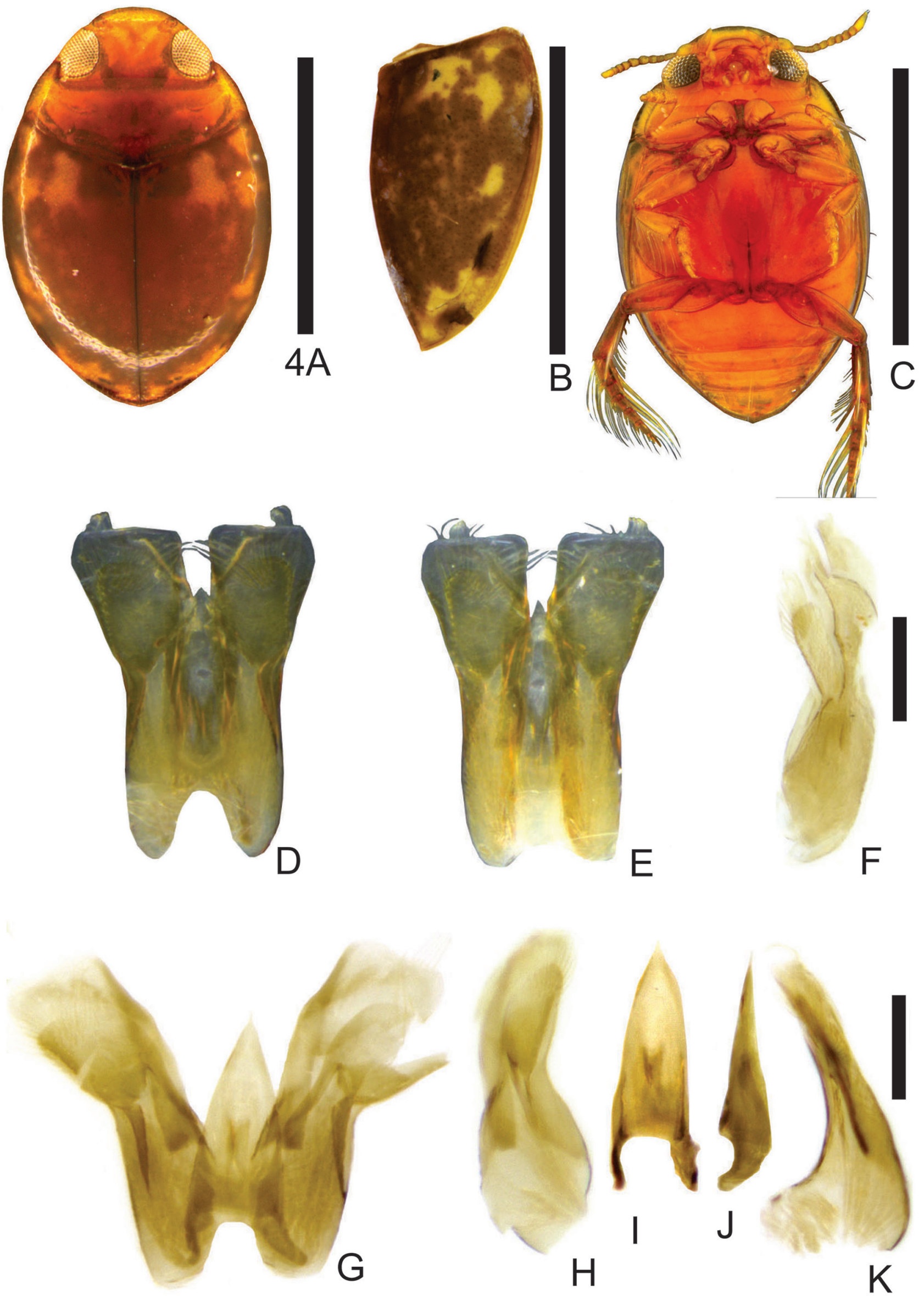

Figures 4A-K. Desmopachria yanomami. (A) Dorsal View. (B) Colour pattern of elytron. (C) Ventral view. (D-K) Male genitalia. (D) Dorsal view. (E) Ventral view. (F) Lateral view. (G) Coverslip dorsal view. (H) Lateral lobe dorsal view. (I) Median lobe dorsal view. (J) Median lobe lateral view. (K) Lateral lobe lateral view. Figs. 4A-C scale bars $=1 \mathrm{~mm}$, Figs. 4D-K scale bars $=0.1 \mathrm{~mm}$. 
Type material: Holotype male: "Brasil, Amazonas, Barcelos,/ Igarapé do Tabocal,/ 0000'57"S, 6248'38"W,/ 08.viii.2009, Ferreira-Jr N. \& Nessimian, J.L., AJ17 [paper white label]", "5955 [plastic blue label]" "HTYPE [plastic red label]" (DZRJ). Paratypes: "Brasil, Amazonas, Barcelos,/ Igarapé do Tabocal,/ 0000'57"S, 6248'38"W,/ 08.viii.2009, Ferreira-Jr N. \& Nessimian, J.L., AJ17 [paper white label]", "5956 [plastic blue label]", "PTYPE [plastic red label]" (35 exs.) (DZRJ).

Taxonomic notes: This new species belongs to the D. ubangoides group sensu Miller (2001) having the anterior clypeal margin sexually dimorphic, males being strongly modified, thin, translucent and strongly upturned, and being anteriorly beaded in the female. This species is near D. minuta Young 1980 in colour pattern and in the shape of the genitalia, but can be separated from it by the bigger size, presence of transversal suture on last sternite, a character only shared in this group with D. ubangoides, and the apex of the male median lobe being pointed instead of bifurcated and dorsal rami of lateral lobe are broad instead of slender.

Etymology: The species name refers to masculine and feminine noun "Yanomâmi", the name of the indigenous people present in the area of origin of the type material. It is a noun in the nominative singular standing in apposition.

Geographic distribution: Known only from the Amazonas State of Brazil.

\section{Desmopachria nigricoxa sp. nov. (Figures 5A-K)}

Diagnosis: Large size for the genus 2.3-2.4 mm. Male median smaller than the lateral lobe with wide apex (Figs. 5D-F); Lateral lobes in dorsal almost S-shaped (Fig. 5H).

Description: Holotype male: total length $2.4 \mathrm{~mm}$; maximum width of body $1.8 \mathrm{~mm}$; elytral length $1.6 \mathrm{~mm}$; maximum width of the pronotum $1.4 \mathrm{~mm}$.

Colouration (Figs. 5A-C): Head light brown; pronotum light brown with base dark brown (Fig. 5A); each elytron dark brown with elytral suture area darker and a lateral light brown (Fig. 5B); venter light brown with exception of dark brown metacoxae (Fig. 5C).

Structure and sculpture: Body rounded with dense punctuation; punctures fine and deep in dorsal surface; elytral surface with a line of very fine and deep punctuations, in ventral surfaces sparsely distributed punctuations large and shallow. Clypeus truncated; antennae with rounded scape, pedicel narrower and longer than others antennomeres, antennomeres 5-9 slightly expanded in apical half. Pronotum short and wide, without basal striae and lateral bead; pros- ternal process apically strongly forked, area between rami forming a deep pit. Elytral suture without margin with a parallel line of very coarse and deep punctures. Ventral surface of metatibia covered with short and wide spines. Apical ventrite smooth without sutures or marks.

Male genitalia (Figs. 5D-K): Median lobe of aedeagus three quarter longer than lateral lobes (Figs. 5D-G); in dorsal view gently narrowing, apex arched (Fig. 5l); in lateral view basal third broad, apical and middle third narrowing and bended to dorsal view, apex rounded (Fig. 5J). Lateral lobes in dorsal view almost S-shape with a dense row of setae on inner margin of apical half (Fig. $5 \mathrm{H}$ ); in lateral view basal third expanding towards, middle and apical third rectangular (Fig. 5L).

Intraspecific variation: Small variations in length and width: Total length 2.3-2.5 mm; maximum width $1.6-1.7 \mathrm{~mm}$.

Type material: Holotype male: "Brasil, Mato Grasso, Chapada dos/ Guimarães, Parque Nacional da/ Chapada dos Guimarães,/ Cachoeira Marimbondo,/ 15²2 $60^{\prime \prime} \mathrm{S}$, 55 43'12"W,/ 01.iii.2016, Ferreira-Jr N. \&/ Guimaraes B., MTNB01 638 m [paper white label]", "5964 [plastic blue label]" "HTYPE [plastic red label]" (DZRJ). Paratypes: "Brasil, Mato Grasso, Chapada dos/ Guimarães, Parque Nacional da/ Chapada dos Guimarães,/ Cachoeira Marimbondo,/ $15^{\circ} 25^{\prime} 60^{\prime \prime} \mathrm{S}$, 5543'12"W,/ 01.iii.2016, Ferreira-Jr N. \&/ Guimaraes B., MTNB01 638 m [paper white label]”, "5962 [plastic blue label]", "PTYPE [plastic red label]" (4 exs.) (DZRJ).

Taxonomic notes: This new species belongs to the D. portmanni group sensu Miller (2001) having the prosternal process sexually dimorphic. The combination of the male median lobe having a wide apex and being smaller than the lateral lobe, as well as the large body size is distinctive for this species. Desmopachria minuta Sharp 1882 and D. amyae Miller 2001 both have a male median lobe with a wide apex but their medium lobe lenghts are almost the same to those of the lateral lobe and their body sizes are smaller than $D$. nigricoxa sp. nov. The species D. aurea Young 1980, D. variegata Sharp 1882 and $D$. specula Sharp 1887 have the male median lobe much smaller than the lateral lobe but do not have the wide apex and are also have body size smaller than this new species. Desmopachria bryanstoni Clark 1862 and D. zetha Young 1995 are similar in the length of the body and male median lobe but the apex of the male median lobe is narrower.

Etymology: The specific name is formed by a combination of the Latin adjective "nigra" meaning dark and the noun "coxa" meaning thigh, referring to the metacoxae colour.

Geographic distribution: Known only from the Mato Grosso State of Brazil. 

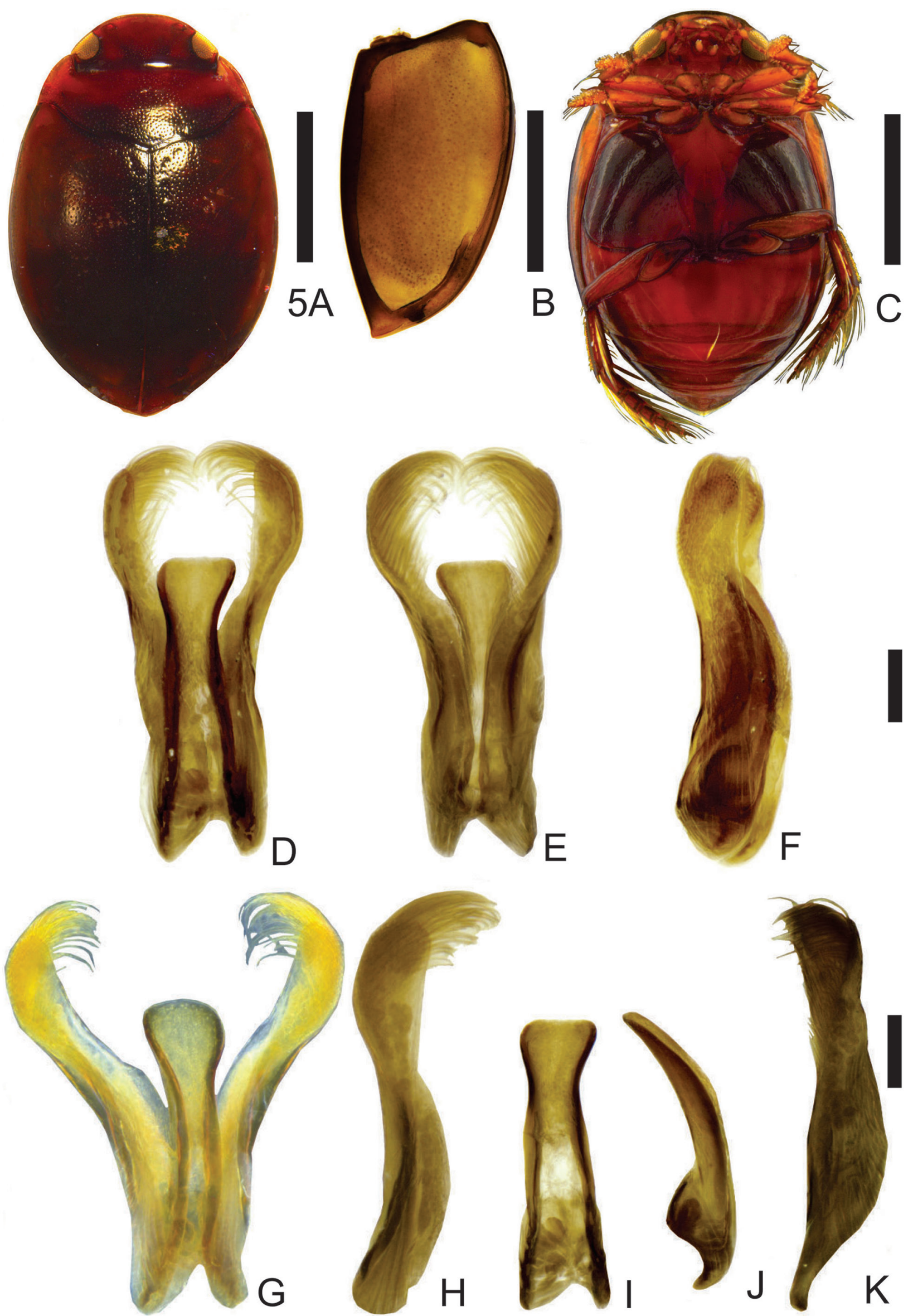

Figures 5A-K. Desmopachria nigricoxa. (A) Dorsal View. (B) Colour pattern of Elytron. (C) Ventral view. (D-K) Male genitalia. (D) Dorsal view. (E) Ventral view. (F) Lateral view. (G) Coverslip dorsal view. (H) Lateral lobe dorsal view. (I) Median lobe dorsal view. (J) Median lobe lateral view. (K) Lateral lobe lateral view. Figs. $5 \mathrm{~A}-$ - c scale bars $=1 \mathrm{~mm}$, Figs. $5 \mathrm{D}-\mathrm{K}$ scale bars $=0.1 \mathrm{~mm}$. 


\section{Desmopachria nigrisphera sp. nov. (Figures 6A-K)}

Diagnosis: Medium size for the genus $1.8 \mathrm{~mm}$; body very rounded, shiny black with dense punctures (Fig. 6A). Male median lobe in dorsal view straight parallel-sided with apex rounded (Fig. $6 \mathrm{~J}$ ) with almost the same length than lateral lobes (Fig. 6D).

Description: Holotype male: total length $1.8 \mathrm{~mm}$; maximum width of body $1.3 \mathrm{~mm}$; elytral length $1.2 \mathrm{~mm}$; maximum width of the pronotum $0.9 \mathrm{~mm}$.

Colouration (Figs. 6A-C): Dorsal view shiny black with exception of the brown inner margin of pronotum (Figs. 6A-B); venter shiny black with exception of head, prosternum and legs testaceous (Fig. 6C).

Structure and sculpture: Body very rounded. Head with fine and shallow scarcely distributed punctures; pronotum with fine and shallow scarcely distributed punctures and course and deep punctures near base and in a line parallel the apical margin; elytral surface with fine and shallow densely distributed punctures and a line of fine and deep punctures in disc. Clypeus beaded; antennae with rounded scape, pedicel narrower and longer than others antennomeres, antennomeres 5-9 slightly expanded in apical half. Pronotum short and wide, with a lateral bead and without basal striae. Elytral suture margined. Prosternal process apically strongly forked, area between rami forming a deep pit; ventral surface of metatibia covered with short and wide spines. Ventral surface inconspicuous punctuated. Apical ventrite smooth without sutures or marks.

Male genitalia (Figs. 6D-K): Median lobe with almost the same length than lateral lobes (Figs. 6D-G). in dorsal view straight parallel sided apex rounded (Fig. 6I); in lateral view base bilobed and well separated of rest of median lobe, remainder of lobe straight until narrow apical quarter, apex rounded (Fig. 6J). Lateral lobes in dorsal view triangular shape with a dense row of setae on inner margin of apical third (Fig. 6H); in lateral view basal and middle straight almost rectangular, apical third narrowing and bended to inner side (Fig. 6K).

Intraspecific variation: Total length $1.8 \mathrm{~mm}$; maximum width of body 1.1-1.2 mm; elytral length 1.3-1.4 mm; maximum width of the pronotum $0.9-1.0 \mathrm{~mm}$.

Type material: Holotype male:"Brasil, São Paulo, São José do/ Barreiro, Lajeado, Córrego da/ Floresta, Cachoeira do Paredão/ 2243'33"S, 44³7'18"W, /1540 m, 17.xi.2012, Souto PM,/ Ferreira-Jr N, Silveira LFL \&/ Gil-Azevedo LH, BOC13 [paper white label]", "5957 [plastic blue label]" "HTYPE [plastic red label]" (DZRJ). Paratypes: "Brasil, São Paulo, São José do/ Barreiro, Lajeado, Córrego da/ Floresta, Cachoeira do Paredão/ $22^{\circ} 43^{\prime} 33^{\prime \prime} \mathrm{S}, 44^{\circ} 37^{\prime} 18^{\prime \prime} \mathrm{W}$, /1540 m, 17.xi.2012, Souto PM,/ Ferreira-Jr N, Silveira LFL \&/ Gil-Azevedo LH, BOC13 [paper white label]", "5958 [plastic blue label]", "PTYPE [plastic red label]" (3 exs.) (DZRJ).

Taxonomic notes: This new species belongs to the D. portmanni group sensu Miller (2001) in having the prosternal process sexually dimorphic. Although dark dorsal colouration is very common in the portmanni group, most species have small differences in tonality between the head, pronotum, elytrum and ventral surface, only D. grandnigra Braga \& Ferreira-Jr., 2014 and D. nigra Zimmermann, 1923, have a dorsal surface equally dark in all tagma. These two species both have a dorsal surface almost impuctate giving a vitreous aspect which is absent in the new species. Desmopachria bryanstoni Clark, 1862, D. pittier Young, 1995 D. zetha Young, 1995 and D. goias Young, 1995 have male genitalia which are similar in shape to Desmopachria nigrisphera sp. nov. but the former three species are bigger in body size.

Etymology: The specific name is a combination of the Latin adjective "nigra" meaning dark and the substantive "sphere" meaning ball, referring to the colour and shape of this species.

Geographic distribution: So far known only from the São Paulo State of Brazil.

\section{Desmopachria varians Wehncke 1877 (Figures 7A-L)}

Diagnosis: This species is characterised by its size, large among Desmopachria species (2.2-2.7 $\mathrm{mm}$ ), for the characteristic elytral macula pattern (Fig. 7C), for the presence of a transversal and waved suture in last segment (Fig. 7D) and for the peculiar male genitalia (Figs. G-N).

Description: Total length $2.2-2.7 \mathrm{~mm}$; maximum width of body 1.6-1.7 mm; elytral length 1.5-1.9 mm; maximum width of the pronotum 1.2-1.3 $\mathrm{mm}$.

Colouration (Figs. 7A-C): Head yellow, pronotum yellow with brown macula at base (Figs. 7A and C); each elytron yellow with elytral suture dark and two brown longitudinal fasciae parallel to elytral suture, the inner fascia fused with suture in middle and the apical tip of outer fascia touch the inner in the apical quarter (Fig. 7C). Ventral surface testaceous with exception of light brown metasternum and metacoxa (Fig. 7B).

Structure and sculpture: Body globular with head inconspicuously punctate; Pronotum and each elytron with coarse deep and very dense distributed punctures. Clypeus beaded; antennae with rounded scape, pedicel narrower and longer than others flagellomeres, antennomeres 5-9 slightly expanded in apical half. Pronotum short and wide, with a lateral bead and without basal striae; pro- and mesotarsus with ventral adhesive setae; prosternal process broad, apically rounded, shallowly concave. Elytral suture margined. Ventral surface very 

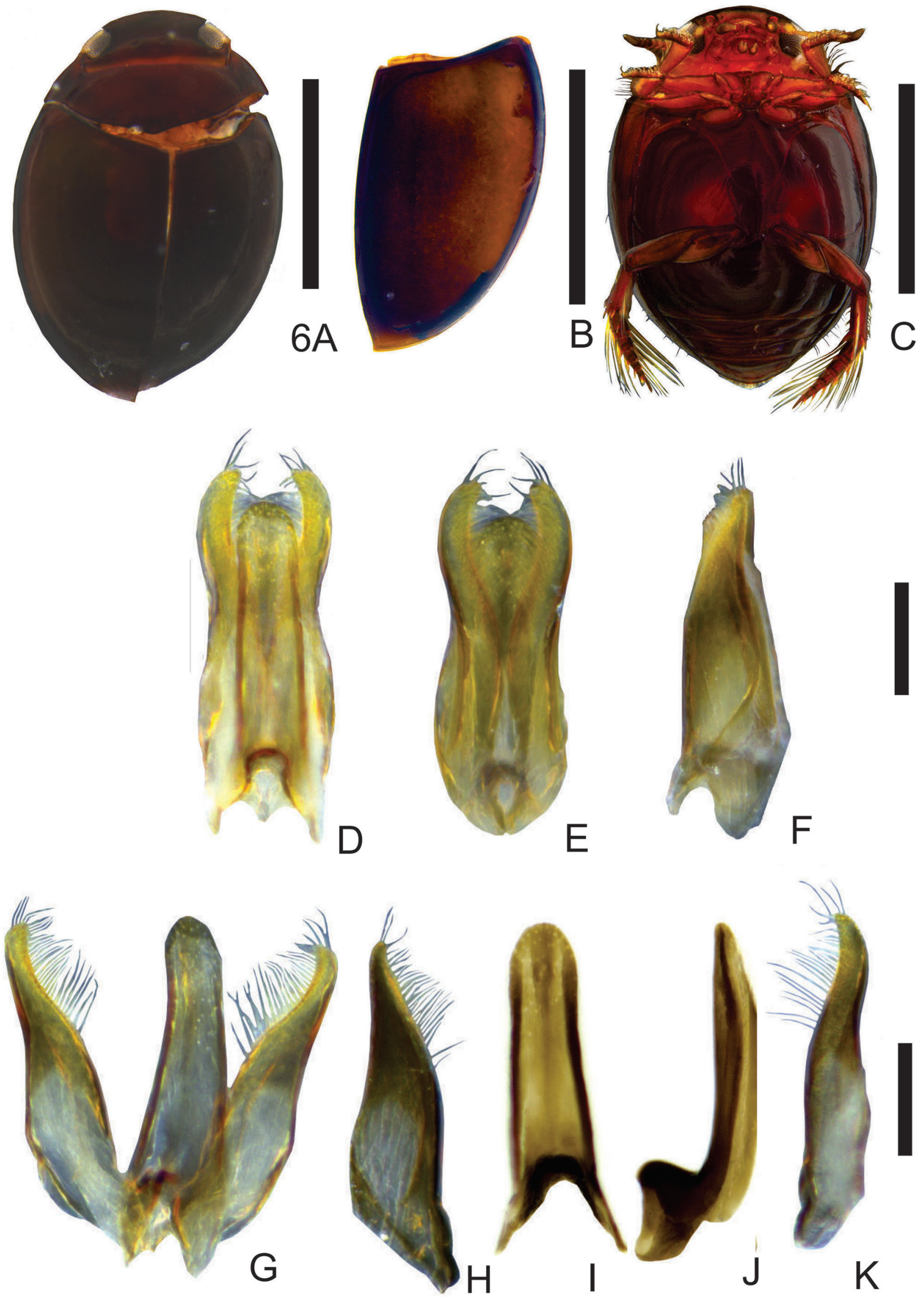

Figures. 6A-K. Desmopachria nigrisphera. (A) Dorsal View. (B) Colour pattern of Elytron. (C) Ventral view. (D-K) Male genitalia. (D) Dorsal view. (E) Ventral view. (F) Lateral view. (G) Coverslip dorsal view. (H) Lateral lobe dorsal view. (I) Median lobe dorsal view. (J) Median lobe lateral view. (K) Lateral lobe lateral view. Figs. $6 \mathrm{~A}-\mathrm{C}$ scale bars $=1 \mathrm{~mm}$, Figs. 6D-K scale bars $=0.1 \mathrm{~mm}$. 


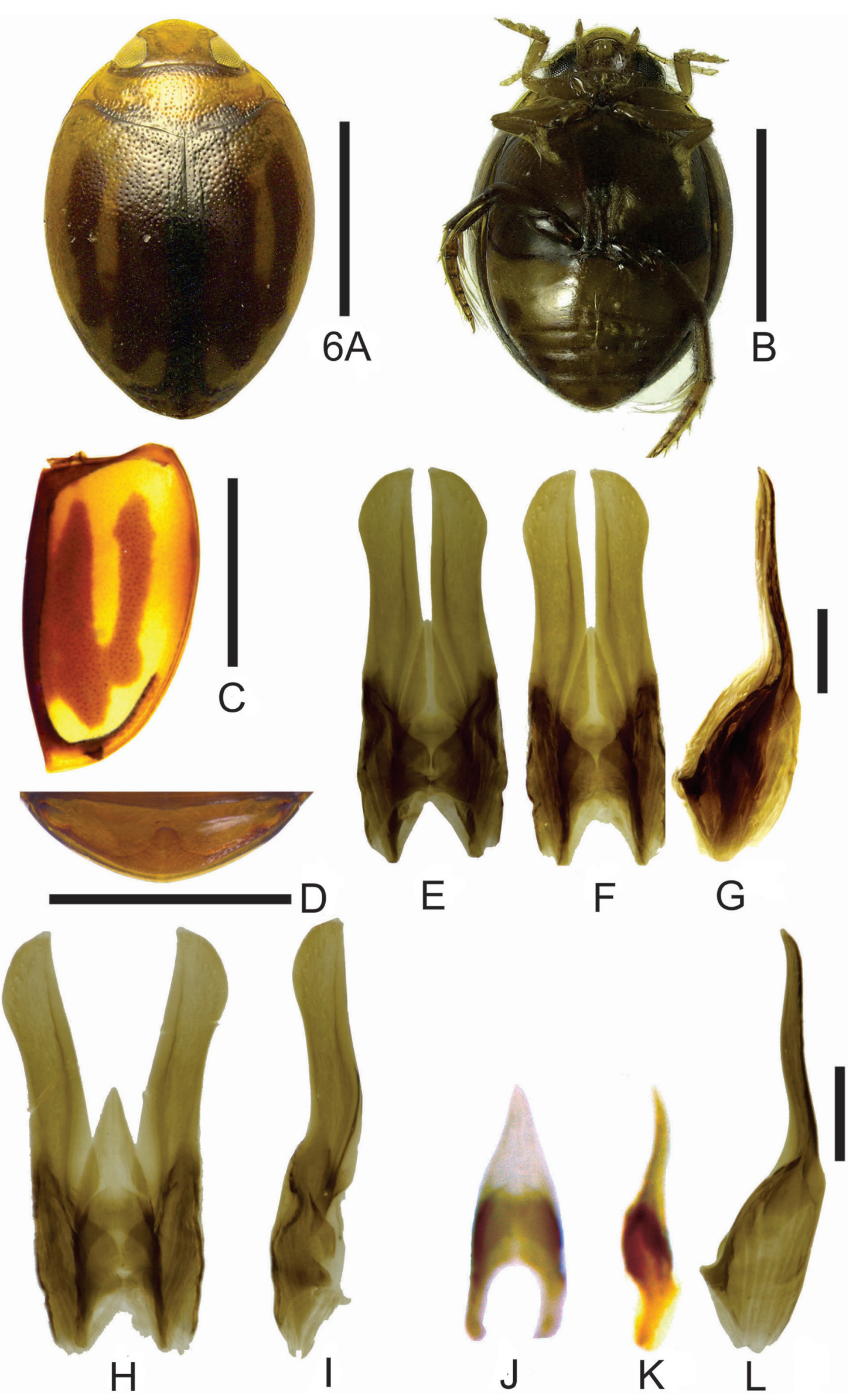

Figures 7A-L. Desmopachria varians. (A) Dorsal View. (B) Ventral view. (C) Colour pattern of Elytron. (D) Apical ventrite. (E-M) Male genitalia. (E) Dorsal view. (F) Ventral view. (G) Lateral view. (H) Coverslip dorsal view. (I) Lateral lobe dorsal view. (J) Median lobe dorsal view. (K) Median lobe lateral view. (L) Lateral lobe lateral view. Figs. $1 \mathrm{~A}-\mathrm{D}$ scale bars $=1 \mathrm{~mm}$, Figs. 1E-L scale bars $=0.1 \mathrm{~mm}$. 
fine, with shallow and scarcely distributed punctures. Ventral surface of metatibia covered with short and wide spine. Apical ventrite with conspicuous waved sutures (Fig. 7D).

Male genitalia (Figs.7E-L): Median lobe of aedeagus very short, half the length of lateral lobes (Figs. 7E-F and H); in dorsal view basal half parallel-sided and apical half triangular, narrowed toward apex (Fig. 7J); in lateral view basal half broader and apical half bended to ventral side and narrowing to pointed apex (Fig. 7K). Lateral lobes in dorsal view almost parallel with inner margin straight until apex and outer margin rounded to apex in apical forth, giving an overall semicircular looking to the apex (Fig. 7l); in lateral view basal half broad almost oval and apical half very thin and discretely sinuate (Fig. 7L).

Examined material: BRAZIL. Alagoas State: Delmiro Gouveia Municipality, Lagoinha [09²6'24"S, 38 01'48"W], 20-25.iii.1992, Sachsse R. (60 exs. DZRJ 656); Olho d'água do Casado Municipality, Fazenda Sr. Luis do Chalé, Chesf Ingerio EIA Xingó, [09³0'00"S, 3749'48"W], 18.iii.1992, Sachsse R. (6 exs. DZRJ 645). Amazonas State, Novo Airão Municipality, Anavilhanas Archipelago, Lago do Prato 03.v.1981 Jorge Luiz Nessimian. (1 ex. DZRJ 2688). Bahia State: Caetité Municipality, Distrito Uranifero Lagoa Real, INB, [14 $\left.03^{\prime} 36^{\prime \prime} S, 42^{\circ} 29^{\prime} 24^{\prime \prime} \mathrm{W}\right]$, 08-16.i.2000, Nessimian [2044'44"S, 6044'42"W], J.L. \& Baptista D.F. Horto (2 exs. DZRJ 2676), Bacia de Decantação (6 exs. DZRJ 2672); Encruzilhada Municipality, 07.xi.1972, M Alvarenga BLT, det. FN Young. (1 ex. USNM). Minas Gerais State, Manga Municipality, Mocambinho, Agroceres, [14 45'21"S, 435'55"W], 22-25.x.1992, Carvalho A.L. (4 exs. DZRJ 2674). Rio de Janeiro State, Cabo Frio Municipality, Ilha do Cabo Frio, Lago, [22 $52^{\prime} 46^{\prime \prime S}, 42^{\circ} 01^{\prime} 07^{\prime \prime}$ ] $]$, 14-27.i.1984, Sampaio, Carvalho \& Kosawa (7 exs. DZRJ 333).

Taxonomic notes: First included by Young (1980) in the subgenus Pachriostrix Guignot, 1950, this species was then moved to the subgenus Pachriodesma Guignot, 1949 by Young (1990b) and finally considered impossible to be inserted in a known species groups by Miller (2001) and yet remain ungrouped. The sutural striae on elytra indicate $D$. varians should be placed in the $D$. striola group, however, this stria was also found in species belonging to other groups, such as $D$. anuine, $D$. carranca and $D$. nigrisphera, demonstrating that sutural striae is a relatively weak character for inferring relationship, problem already highlighted by Miller (2001).

The bright elytral colour pattern of this species with longitudinal brown maculae is typical of the $D$. dispersa group, but $D$. varians does not have the characteristic basal striae on the pronotum of $D$. dispersa group. The shape of male genitalia, with triangular median lobe very small in comparison with lateral lobes which are flat, almost parallel in dorsal view, is only comparable to $D$. chei Miller, 1999 and D. rex Gustafson \& Miller, 2012, but both species lack elytral macula and $D$. rex is much larger than D. varians.
Geographic distribution: This species was only known from Bahia and Ceará states in Brazil. Its distribution is here expanded to the Brazilian states of Alagoas, Amazonas, Minas Gerais and Rio de Janeiro.

\section{New records from Brazi}

\section{Desmopachria amyae Miller 2001}

Minas Gerais State: Chapada dos Guimarães Municipality, Cachoeira Marimbondo, 15²5'60"S, $55^{\circ} 43^{\prime} 12^{\prime \prime}$ W. 01.iii.2016, Ferreira-Jr., N. \& Guimarães, B. (2 exs. DZRJ 5961).

\section{Desmopachria challeti Miller 2001}

Rio de Janeiro State: Teresópolis Municipality, Albuquerque, Rio Varginha, represa, $22^{\circ} 26^{\prime} 49^{\prime \prime} S$, $42^{\circ} 53^{\prime} 22^{\prime \prime}$ W. 07.vii.1996, Ferreira-Jr., N. (6 exs. DZRJ 2665).

\section{Desmopachria grammosticta \\ Braga \& Ferreira-Jr., 2015}

Minas Gerais State: Itamonte Municipality, Rio Aiuruoca, poças, $22^{\circ} 20^{\prime} 59^{\prime \prime} S, 44^{\circ} 41^{\prime} 55^{\prime \prime}$ W. 08.iv.2005 Ferreira-Jr., N. \& Santos, A.D. (9 exs. DZRJ 5977).

São Paulo State: São José do Barreiro Municipality, Lajeado, Córrego da Floresta, Cachoeira do Paredão $22^{\circ} 43^{\prime} 33^{\prime \prime S}, 44^{\circ} 37^{\prime} 18^{\prime \prime}$ W. 1,540 m alt., 17.xi.2012, Souto, P.M.; Ferreira-Jr., N.; Silveira, L.F.L. \& Gil-Azevedo, L.H., BOC13. (4 exs. DZRJ 5975); Ubatuba Municipality, Parque Estadual da Serra do Mar, Núcleo Picinguaba, $23^{\circ} 21^{\prime} 34^{\prime \prime}$ S, 4450'31"W. 07.vi.2008, Ferreira-Jr., N. (3 exs. DZRJ 5976).

\section{Desmopachria granoides Young 1986}

Espirito Santo State: São Mateus Municipality, São Mateus, $18^{\circ} 44^{\prime} 33^{\prime \prime}$ S, 3948'38"W. 01.xii.2007. (1 ex. DZRJ 5986).

\section{Desmopachria laevis Sharp 1882}

Espirito Santo State: Itarana Municipality, Estrada Laranja da Terra, Riacho com correnteza, [19'52'13"S, 4057'49"W], 27.ii.2009, Moreira, F.F.F. ES02 (7 exs. DZRJ 5999); Iuna Municipality, Serra do Caparaó, Rio Claro, Cachoeira do Rogério: poça na mata, 20²2'05"S, 4149'51"W. 07.x.2010, Ferreira-Jr., N., 1071 m (11 exs. DZRJ 5933); poça na pedra c/ folhiço, 07.x.2010 (18 exs. DZRJ 5995); laje c/ musgo e filete d'água, 07.x.2010 Ferreira-Jr., N. (1 ex. DZRJ 5989).

Parana State: Jaguariaiva Municipality, Parque Estadual do Cerrado: Ribeirão Santo Antônio, 2410'4.7"S, 4940'3.3"W. 20.iv.2014, Sampaio, B.H.L., Guimarães, B.A.C., Ferreira-Jr., N. (42 exs. DZRJ 5998). 


\section{Desmopachria leptophallica Braga \& Ferreira-Jr. 2014}

Pará State: Parauapebas Municipality, Floresta Nacional de Carajás: Buritizal I, leito do rio, Fundo de folhiço em poça, $06^{\circ} 04^{\prime} 57^{\prime \prime}$, $50^{\circ} 08^{\prime} 05^{\prime \prime}$ W. 23.ix.2007, Ferreira-Jr., N. \& Alecrim, V.P. (11 exs. DZRJ 5968); lago N5sul, 0605'50.01"S, $50^{\circ} 07^{\prime} 50.08^{\prime \prime} W$. iii.2005, Ferreira-Jr., N. (7 exs. DZRJ 5969)

\section{Desmopachria sioli Young 1980}

Minas Gerais State: Marliéria Municipality, Parque Estadual do Rio Doce/CAF, Ribeirão do Turvo, Folhiço

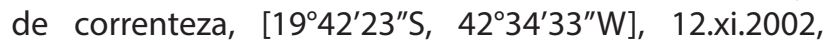
Francischetti, C.N. \& TLF (10 exs. DZRJ 5954)

\section{Desmopachria striola Sharp 1887}

Rio de Janeiro State: Macaé Municipality, Rio Macaé, 28.vii.2004, Ferreira-Jr., N. (2 exs. DZRJ 2692); Magé Municipality, Citrolândia, $\left[22^{\circ} 06^{\prime} 01^{\prime \prime S}, \quad 43^{\circ} 01^{\prime} 23^{\prime \prime} \mathrm{W}\right]$, 13.x.1994, Ferreira-Jr., N. (1 ex. DZRJ 2694). Maricá Municipality, Restinga de Maricá, $22^{\circ} 55^{\prime} 09^{\prime \prime} \mathrm{S}, 42^{\circ} 49^{\prime} 06^{\prime \prime} \mathrm{W}$. 13.iii.1987, Ferreira-Jr., N. (10 exs. DZRJ 116).

São Paulo State: Ubatuba Municipality, Parque Estadual da Serra do Mar, Núcleo Picinguaba, 2321'34"S, 4450'31"W. 07.vi.2008, Ferreira-Jr., N.; 30.vi.2006, Braga, R.B. (30 exs. DZRJ 5979); 03.vi.2011, Ferreira-Jr., N. \& Moraes, C. (2 exs. DZRJ 5978).

\section{Desmopachria volatidisca Miller 2001}

ParaíbaState:ItapororocaMunicipality, RioMamanguape, Fazenda Santíssimo, [06 $50^{\prime} 20^{\prime \prime}$ S, 3507'33"W], 07.ix.2001, Francischetti, C.N. (1 ex. DZRJ 5965).

\section{ACKNOWLEDGEMENTS}

We wish to express our special thanks to G. Gustafson and M. Leister for the English revision, A. Mantilleri from Muséum National D'Histoire Naturelle (MNHN, Paris) for the Syntypes photos and N.S. Amparo and S. Jorge for support. Financial support was granted by Coordenação de Aperfeiçoamento de Pessoal de Nível Superior (CAPES), Conselho Nacional de Desenvolvimento Científico e Tecnológico (CNPq, Brazil) and Fundação Carlos Chagas Filho de Amparo à Pesquisa do Estado do Rio de Janeiro (FAPERJ).

\section{REFERENCES}

Braga, R.B. \& Ferreira-Jr., N. 2010. Four new species of Desmopachria Babington (Insecta, Coleoptera, Dytiscidae) from the Amazon river floodplain. Zootaxa, 2415: 33-42.
Braga, R.B. \& Ferreira-Jr., N. 2011. Two new species of Desmopachria Babington, 1841 (Coleoptera: Dytiscidae) from Brazil. Aquatic Insects, 33(2): 127-131.

Braga, R.B. \& Ferreira-Jr., N. 2014. Carnivorous diving beetles of the genus Desmopachria (Coleoptera: Dytiscidae) from Brazil: New species, new records, and a checklist. Journal of Insect Science, 55: 1-26.

Gustafson, G.T. \& Miller, K.B. 2012. A new species of Desmopachria Babington from Venezuela (Coleoptera: Dytiscidae: Hydroporinae). Koleopterologische Rundschau, 82: 71-76

Miller, K.B. 1999. Descriptions of eight new species of Desmopachria Babington 1841 from Bolivia (Coleoptera: Dytiscidae: Hydroporinae: Hyphydrini). Entomologica scandinavica, 30: 349-359.

Miller, K.B. 2001. Descriptions of new species of Desmopachria Babington, 1841 (Coleoptera: Dytiscidae: Hydroporinae: Hyphydrini) with a reassessment of the subgenera and species groups and a synopsis of the species. The Coleopterists Bulletin, 55(2): 219-240.

Miller, K.B. 2005. Four new species of Desmopachria Babington from Peru (Coleoptera: Dytiscidae).Zootaxa, 1059: 39-47.

Miller, K.B. \& Wolfe, G.W. 2018. Nine new species in the Desmopachria nitida Species-Group of the neotropical Genus Desmopachria Babington, 1841 (Coleoptera: Adephaga: Dytiscidae: Hydroporinae: Hyphydrini). The Coleopterists Bulletin, 72(1): 97-112.

Nilsson, A.N. \& Hájek, J. 2018. A World Catalogue of the Family Dytiscidae, or the Diving Beetles (Coleoptera, Adephaga). Version 1.I.2018. Distributed by the authors: www.waterbeetles.eu/documents/W CAT Dytiscidae 2018.pdf. Access in: 11/05/2018.

Sharp, D. 1882. On aquatic carnivorous Coleoptera or Dytiscidae. Scientific Transactions of the Royal Dublin Society, (2) 2: 179-1003.

Wehncke, E. 1877. Neue Dytisciden. Stettiner Entomologische Zeitung, 38: 150-152.

Young, F.N. 1980. Predaceous water beetles of the genus Desmopachria Babington: the subgenera with descriptions of new taxa (Coleoptera: Dytiscidae). Revista de Biologia Tropical, 28: 305-321.

Young, F.N. 1981a. A new name for Hintonia Young, a subgenus of Desmopachria. The Coleopterists Bulletin, 35: 212.

Young, F.N. 1981b. Predaceous water beetles of the genus Desmopachria Babington: the convexa-grana group (Coleoptera: Dytiscidae). Occasional Papers of the Florida State Collection of Arthropods, 2: 1-9.

Young, F.N. 1981c. Predaceous water beetles of the genus Desmopachria Babington: the leechi-glabricula group (Coleoptera: Dytiscidae). PanPacific Entomologist, 57: 57-64.

Young, F.N. 1986. Predaceous water beetles of the genus Desmopachria Babington: the nitida-group (Coleoptera: Dytiscidae). The Coleopterists Bulletin, 40: 269-271.

Young, F.N. 1989. A new species of Desmopachria (s. str.) from the AntilleanCaribbean region (Coleoptera: Dytiscidae). Psyche, 96: 307-309.

Young, F.N. 1990a. New Neotropical species of Desmopachria (Desmopachria S. str.) Babington (Coleoptera: Dytiscidae). Insecta Mundi, 4: 1-4.

Young, F.N. 1990b. Predaceous water beetles of the genus Desmopachria Babington: the subgenus Pachriostrix Guignot (Coleoptera: Dytiscidae). The Coleopterists Bulletin, 44: 224-228.

Young, F.N. 1993. A new species of Desmopachria (Desmopachria) Babington from Brazil (Coleoptera: Dytiscidae). The Coleopterists Bulletin, 47: 245-246.

Young, F.N. 1995. The genus Desmopachria Babington, subgenus Portmannia Young (Coleoptera: Dytiscidae). Insecta Mundi, 9: 37-45. 